The currents and composition of the atmosphere, particularly above water, are equally interesting to the hydrobiologist, because water is the medium of transport of great quantities of nutrients.

However, it is the surface of the earth which still attracts the greatest attention, and it is here that the aeroplane is unsurpassed for photographic work. It is unnecessary to state the advantages in speed and accuracy of this method for preparing maps. The French Geographical Institute has been allotted a squadron of special aireraft to prepare within a reasonable period maps of territories overseas.

The immediate rewards of air survey are of a morphological character and are related to physical geography: tectonic phenomenon, erosion, and hydrological events are clearly visible. Aerial photography is used in regular hydrographic surveys to plot the topography of the coast and of the bottom of the sea. It is also considered possible to study sea surges by aerial photography and photogrammetric methods. The evolution of the coast-line by sea erosion can, of course, be readily followed by this means.

In France, aerial photography is being used for the preparation of maps of vegetation $(1: 200,000)$ for both the pure or applied botanist. This work is undertaken by the National Centre of Scientific Research, and is being used to plot classified forest and other reserves. Overseas, photography will allow the survey of remote and secluded areas of vegetation (different types of forest, savannas, etc.).

Again, photography from the air gives more complete information about the distribution of man on the earth, and is thus of interest to the archæologist, the prehistorian and ethnographer. Aerial photography has proved a trustworthy method of studying the past. By making use of oblique background lighting, it makes clear organisations and communities of thousands of years ago. Father Poidebard, so early as 1925. discovered in Syria the details of the line of contact between the Romans and the desert tribes of the Euphrates region. In his last expedition, finishing in 1939, he constructed a plan of the economic organisation of Upper Roman Syria. The novelty of the method employed consisted in combining epigraphic research with the reconnaissance aeroplane. In the buried ruins found in the desert, the first details that appear when seen from a high altitude are the entrances to the buildinge and towns; it is there that important inscriptions are found which fix the date of origin. Aerial photography also allows us to locate ancient remains even when the ground is level ; for vegetation generally flourishes more vigorously on the foundations of ancient buildings, mounds and ditches; and it turns yellow more quickly on the sites of paths and walls.

But the earth is above all the setting for human phenomena ; migrations, pilgrimages, battles, engagements and deployments of troops may be assessed. by studying the photographs.

By means of aerial photographs it is possible to fix the transformations of natural boundaries during annual and seasonal variations due to the rotation of crops. Again, slower variations, digressions, alterations or extensions of certain operations of Nature or man have an insensible effect otherwise difficult to assess : such as the regression of grazing land on the high Algerian plateau, the instability of river banks in the north Cameroons and the shrinking of vegetation in certain tropical countries. It reveals the movements of the subsoil, upon the fertility of which mankind depends.
Aorial photography contributes more than psychological aid to the ethnographist carrying out researches on the ground. It constitutes an incomparable method for investigating the human race, presenting a true picture of its disposition. Aørial photographs are also intelligible to primitive peoples, after a certain amount of instruction, as opposed to maps, which remain a closed book to them. It also penetrates real secrets in revealing hidden villages and clearings in forestry reserves; and more particularly in dis. closing the details of walled courts, terraces and enclosures which are hidden from terrestrial exploration. It equally allows the establishment of an exact and detailed topography which may make apparent otherwise inexplicable phenomena on maps (sacred ruins, mythical voyages, etc.).

The aeroplane is one of the most precise tools for scientific research on the progress of human evolution and for examining the natural boundaries of the earth. This task is still only in its early stages. With the aeroplane used on the grand scale, the problem will be completed in decades instead of the centuries which would be required by the classical methods of investigation.

\section{PHYSICAL PROPERTIES OF MICA}

$\mathrm{M}$ ICA is so critical a material for the manufacture of electrical equipment that, during the War, it was often referred to as "the most important single war material". Without it there would probably not have been any radio or radar, gun control or detector devices. In peace-time, mica is equally important for it is an indispensable component of many domestic and industrial electrical appliances. It is used in condensers, radio valves, heating elements, X-ray apparatus, electrical machinery, temperature control apparatus, etc., and is preferred to other good electrical insulators because it can also be split easily to any desired thickness. As a component of such appliances it is naturally subjected to all kinds of varying physical conditions and it is therefore essential to have an accurate knowledge of the physical properties of mica.

As an outgrowth of certain tests made in connexion with a military problem, P. Hidnert and G. Dickson have obtained data on the linear thermal expansion, changes in structure, power factors, and effects of heat treatment on thickness, opacity, and colour of micas (Bur. Stand. J. Res., 35, 309; 1945). Fifty samples in all, consisting of five types of micas (muscovite, phlogopite, biotite, ripidolite and zinnwaldite), from different sources and of different qualities, were examined. No chemical analyses were made of the samples.

For the thermal expansion measurements, the fused-quartz tube apparatus of Hidnert and Sweeney (Bur. Stand. J. Res., 1,771 ; 1928) was modified, so that short cylindrical specimens of mica could be used. All the thirty samples investigated were under load (about $2 \mathrm{kgm} . / \mathrm{cm}^{2}$ ) when the measurements were made. Results are given for the linear thermal expansion in the direction perpendicular to the cleavage plane over the range $20^{\circ} \mathrm{C}$. to $600^{\circ} \mathrm{C}$. (in some cases $700^{\circ}$ C.). A few of the phlogopite and biotite samples have extremely high coefficients of expansion, many times that of any other known solid material. These micas, in combination with a metal, alloy or non-metallic material, would, when heated or cooled, produce a large differential expansion or contraction. They are, therefore, most useful as high- 
expanding elements in temperature control and indicating devices. They would prove, however, unsatisfactory, yet perfectly good electrical insulators, in applications where large changes in dimensions with changes in temperature are not desired.

The section on changes of structure is contributed by H. C. Vacher. Laue X-ray diffraction photographs were taken of several samples at room temperature and at elevated temperatures. Transitions which occurred in the expansion curves of two of the phlogopite and one biotite sample appear to be related to the structural changes shown in the corresponding X-ray patterns. The structures of the micas are apparently fragmented by heating, the fragmentation being caused by the independent buckling of very thin layers of the micas parallel to the cleavage planes.

The power factors of several phlogopite and muscovite micas at 100 and $1,000 \mathrm{kc} . / \mathrm{s}$. were determined by E. L. Hall. The details of the method and equipment used have been described elsewhere (Proc. Inst. Rad. Eng., 32, 393 ; 1944). Heat treatment of the samples to $600^{\circ} \mathrm{C}$., with or without load, resulted in an increased power factor for the phlogopite micas but only a slight alteration in the power factor for the muscovite micas.

The effect of heat treatment at $800^{\circ} \mathrm{C}$. on the thickness of muscovite mica was very marked, being as much as 100-150 per cent increase. A Zeiss micrometer, reading to 0.0001 inch and applying a load of about $1 \mathrm{kgm}$. between contacts of $8 \mathrm{~mm}$. diameter, was used for the measurement of the thickness of the specimens. The phlogopite micas were more resistant to heat treatment than the muscovite micas. The large increases in thickness of nearly all the muscovite samples were accompanied by changes from clear or translucent to opaque, or from polychrome to metallic colour.

The detailed results show, on examination, that the thermal expansion, power factor and colour are all largely dependent on such factors as the chemical composition, the nature, magnitude and orientation of the crystals, the presence of impurities and heat treatment. It must, therefore, be concluded that none of the species of mica has fixed and reproducible physical properties.

\section{IMPULSE VOLTAGES AND IRRADIATED SPHERE-GAPS}

A

PAPER by J. M. Meek before the Institution of Electrical Engineers reports the results of experiments made to determine the influence of irradiation on the measurement of impulse voltages with sphere gaps. The impulse breakdown of short gaps between spheres is greatly affected by irradiation and it has been shown already that appreciable errors may be incurred if irradiation is not used with spheres of $6 \cdot 25 \mathrm{~cm}$. diameter in the measurement of voltages up to $100 \mathrm{kV}$. peak. Further measurements have now been made up to $400 \mathrm{kV}$. peak with $1 / 5$ and 1/50 impulse voltage waves of positive and negative polarities, for $6 \cdot 25 \mathrm{~cm}$. and $25 \mathrm{~cm}$. diameter spheres.

Irradiation by the ultra-violet illumination from the impulse generator spark-gaps has a marked influence on the behaviour of the sphere-gap, in the absence of other forms of irradiation. This factor may explain some of the differences between the results obtained by various investigators in the calibration of the sphere-gap with impulse voltages.

The irradiation provided by the insertion of 0.5 $\mathrm{mgm}$. of radium in the high-voltage sphere has also been examined and found to give satisfactory results. With the impulse breakdown of the unirradiated sphere-gap there is a gradual transition from the voltage which causes breakdown for 10 per cent of the applied impulses to that which causes 90 per cent breakdown, whereas a sharply defined breakdown voltage is obtained when the gap is irradiated. The mean breakdown voltage of the unirradiated gap exceeds that of the irradiated gap by an amount which varies with the gap length. For a $3-\mathrm{cm}$. gap between $12.5 \mathrm{~cm}$. spheres, breakdown of the unirradiated gap occurs at a mean voltage about 13 per cent in excess of that for the irradiated gap. With larger gaps, for which a difference between the breakdown voltages for positive and negative impulses is recorded when one sphere is earthed, the difference is found to be influenced largely by irradiation. The mean breakdown voltage for an unirradiated gap of $9 \mathrm{~cm}$. between $12.5 \mathrm{~cm}$. spheres is 20 per cent higher than the irradiated value for a positive impulse, and 1.5 per cent higher for a negative impulse. The negative impulse breakdown voltages agree closely with the corresponding values given in British Standard 358, whereas the voltages given for the positive impulse breakdown are intermediate between those obtained in the present experiments for the unirradiated and the irradiated gaps.

It is evident that irradiation is an important factor in the breakdown of other forms of discharge gaps in which corona is not observed to precede breakdown. Also, the breakdown of discharge gaps on the wavefront may be expected to be governed largely by the amount of irradiation present, and though this has been realized by many workers for short gaps, no consideration appears to have been given to irradiation in the measurement of wave-front breakdown for longer gaps.

\section{THE ONTARIO RESEARCH FOUNDATION}

\begin{abstract}
THE annual report for 1944 of the Ontario Research Foundation includes a list of scientific publications and papers by the members of the staff, during the fifteen years work of the Foundation, to December 31, 1944. The staff has increased to about a hundred, although war-time projects temporarily increased it well beyond that number. Since its establishment, the Foundation has had a broad range of objectives embracing the study of problems in all types of production, but the greater part of the investigations have been in the industrial field, which its facilities and resources are best adapted to serve. Consultative services, testing, short-term studies and long-term investigations have been undertaken for many Canadian firms, and a feature of the Foundation's work is the independent laboratory investigation in advance of industrial demand of fields which show promise of future importance.

During 1944 the demands made on the Foundation exceeded both the available laboratory space and the supply of competent scientific workers. The director, Dr. H. P. Speakman, points out that one
\end{abstract}

